\title{
ADMINISTRAÇÃO MIRIM EM CONDoMíNIO: ANÁLISE DE UMA EXPERIÊNCIA PARTICIPATIVA COM CRIANÇAS
}

\author{
CHILDREN ADMINISTRATION IN A BUILDING: \\ ANALYSIS OF A SHARING EXPERIENCE WITH CHILDREN
}

Regina Zanella Penteado ${ }^{1}$

Administraçáão mirim em condomínio: análise de uma experiência participativa com crianças. Rev. Bras. Cresc. Desenv. Hum., São Paulo, 11(1), 2001.

Resumo: A participação social é essencial para o processo de Promoção da Saúde, e deve ser incentivado desde a infância. O objetivo deste trabalho é apresentar uma análise retrospectiva da experiência de uma Administração Mirim em um Condomínio Residencial, com destaque para os seus fatores intervenientes, suas possibilidades e seus limites. Tal experiência foi uma tentativa de incentivar crianças a participarem de forma ativa e responsável nas questões, decisões e assuntos do edificio que fossem de seus interesses e necessidades. A análise demonstra que a Administração Mirim favoreceu o desenvolvimento individual e coletivo das crianças, que se envolveram de forma participativa em outros eventos e assuntos do edifício, apresentando idéias e buscando solucionar problemas. A análise possibilitou identificar aspectos importantes a serem observados em futuras propostas de Administrações Mirins, como uma contribuição para incentivar a participação social ativa e real, de crianças e adolescentes, em diversos espaços de convívio social.

Palavras-chave: participação social; cidadania; educação popular.

\section{INTRODUÇÃO}

A participação social ativa e real vem sendo considerada como essencial para o processo de Promoção da Saúde, como pode ser constatado na análise do conteúdo das declarações finais das diversas conferências mundiais sobre Promoção da Saúde (MINISTÉRIO DA SAUDE, 2001). A participação, aliam-se as necessidades de acesso à educação, direito de expressão e de compromisso e responsabilidade social para a tomada de decisões e de ações em saúde, dentre outras que favoreçam às pessoas o controle sobre os determinantes da saúde.
Neste trabalho, acredita-se que a capacidade participativa real dos cidadãos de uma sociedade deve ser incentivado e construída desde a infância, a partir das oportunidades cotidianas. Tais oportunidades não devem ser compreendidas unicamente nas relações entre Estado e sociedade civil, mas encontram-se também nas relações sociais cotidianas, nas normas, regras e leis que regem tais relações, nos costumes, nos conflitos e nas estratégias para reconhecer necessidades, identificar problemas, buscar soluções e tomar decisões, tendo em vista o equilíbrio e envolvimento com os interesses coletivos da sociedade.

1 Fonoaudióloga, Mestre e Doutoranda pela Faculdade de Saúde Pública - FSP/USSP. Endereço para contato: Avenida 41 nº 209 ap. 62 - Bairro Cidade Jardim - Rio Claro, SP - CEP 13501-190. E-mail: reginazp@linkway.com.br 
Deste modo, as oortunidades para educação e exercício da cidadania participativa ou cidadania ativa - encontram-se nas relações familiares, nos espaços e relações de moradia, no espaço das instituições educacionais, nos ambientes de trabalho, de lazer, etc.

O objetivo deste trabalho é apresentar uma análise retrospectiva da experiência de uma Administração Mirim em um Condomínio Residencial (de um município do interior do Estado de São Paulo), com destaque para os aspectos positivos, as facilidades, e também para os limites e as dificuldades, correlacionados aos fatores intervenientes que influenciaram os avanços e retrocessos que constituem o seu desenvolvimento. Para tanto, apresentamos o "problema" principal que gerou a iniciativa da Administração Mirim, seguido por um breve relato histórico e a análise de seu processo.

A Administração Mirim foi uma tentativa de incentivar crianças moradoras em um edifício a participarem de forma ativa nas questões e assuntos do condomínio que fossem de seu interesse, especificamente relacionados aos espaços e opções de lazer que o Edifício dispunha. Buscava-se desenvolver, junto às crianças, a conscientização quanto ao uso e preservação dos bens coletivos, à responsabilidade, à expressão de necessidades e à participação nas decisões da Administração do Condomínio, composta pelos adultos. Esperava-se contar com a Administração Mirim como agentes multiplicadores de tais ideários junto às demais crianças do Edificioº .

A análise de uma experiência participativa com crianças requereu esforços na busca de superação das dificuldades em adaptar o referencial teórico, em sua maioria baseado em reflexões sobre os movimentos populares e participação de sujeitos adultos, à realidade e às especificidades de uma prátipativa envolvendo crianças. Esperase, com este estudo, apresentar uma contribuição à literatura sobre educação como construção da participação e da cidadania.

\section{BREVE HISTÓRICO DA ADMINISTRAÇÃ O MIRIM}

A Administração Mirim ocorreu em um curto período de tempo, entre os meses de abril e novembro de 1998, contextualizada em um edifí- cio do município de Rio Claro (SP), após aproximadamente 8 meses da data de entrega/inauguração do prédio.

A caracterização do edifício, que contava com áreas de lazer, favorecia que as famílias que ali morassem fossem, em sua maioria, casais jovens e com filhos na faixa etária entre 3 e 9 anos. Muitas destas famílias viam, naquele edifício, a concretização do sonho da aquisição da primeira moradia própria, uma das razões pelas quais houve, logo de início, um forte espírito de identificação, união e confraternização entre os primeiros moradores.

Naquela época, haviam freqüentes reuniões dos adultos no condomínio, com intensa participação dos novos moradores, já que a preocupação dos adultos voltava-se para a decoração e equipamento dos espaços sociais/áreas comuns. Algumas comissões foram organizadas, inclusive uma destinada à elaboração do projeto e compra de mobiliário e materiais para o "salão infantojuvenil”.

Com a aquisição de brinquedos e jogos e a inauguração do "salão de jogos infanto-juvenil" do Condomínio e com apreocupação dos adultos quanto à manutenção dos bens e materiais recémadquiridos, instaurou-se a necessidade de educação das crianças, moradoras daquele edifício, no sentido do uso coletivo, conservação e manutenção dos materiais e bens do referido salão.

A idéia de instituir a Administração Mirim partiu da psicóloga Larissa Palumbo Bianchi e da fonoaudióloga Regina Zanella Penteado, moradoras do condomínio (na época, ambas sem filhos), que compunham, com mais duas moradoras, a comissão responsável pelo salão.

Com a proximidade da data de entrega e inauguração do salão, a idéia era de que as crianças, a exemplo dos pais (que se encontravam envolvidos com os assuntos coletivos do condomínio), também se envolvessem de forma participativa nas questões de seu interesse imediato no caso, em relação ao novo espaço de convívio e lazer que, para elas, estava sendo preparado.

Assim, esperava-se sensibilizar as crianças para as iniciativas dos adultos em proporcionar um ambiente de bem estar no local em que residiam e despertá-las para participarem, sabendo usufruir das coisas e bens coletivos, conservando-os, sem destruí-los, com senso de responsabilidade e compromisso. Também esperava-se con-

2 Por diversos motivos, a Administração Mirim foi uma experiência que não alcançou uma expressão social mais ampla nem uma adesão e envolvimento de um número significativo de sujeitos. Ainda assim, acreditamos que as reflexões a respeito dos aspectos positivos e negativos desta experiência possam contribuir para sensibilizar as pessoas para as possibilidades de iniciativas de participação popular envolvendo crianças. 
tar com a Administração Mirim como agentes multiplicadores destes ideários junto às demais crianças do edifício.

A Administração Mirim foi oficialmente criada na festa da inauguração do salão, a partir das crianças que lá compareceram e que se mostraram dispostas a assumir as funções de "síndico-mirim” (B.C.Z. - 6 anos), "sub-síndico mirim” (M.G. - 7 anos) e “zelador-mirim” (R.P.M. - 9 anos).

Cabe destacar que, ainda que a intenção inicial das idealizadoras fosse a participação das crianças, a mobilização para a Administração Mirim não se deu a partir das carências ${ }^{3}$, necessidade ou espontaneidade das crianças, mas foi induzida e instituída "de cima" pelas suas idealizadoras, ou seja, os moradores adultos (NUNES, 1989).

Este seria um aspecto importante até mesmo para a construção da identidade daquele grupo de crianças, já que as pessoas se unem ou se agrupam em função de necessidades e objetivos comuns. No entanto, nesta experiência de Administração Mirim, tratou-se de um “poder” atribuído às crianças (pelos adultos) e não por elas conquistado.

\section{ASPECTOS POSITIVOS, POSSIBILIDADES E FACILIDADES}

Enquanto pontos positivos, pode-se destacar que as crianças foram ouvidas sobre os materiais e brinquedos que julgavam ser interessantes para que, depois, fossem selecionados pela comissão de adultos, que definiria o que seria ou não comprado. Também participaram da elaboração e aprovação do regulamento interno do salão, que versava sobre os fins a que se destinava.

Durante os meses de maio a julho, a dinâmica da Administraçao Mirim se deu através de reuniões realizadas no salão, em uma periodicidade quinzenal, com a coordenação das duas profissionais.

Entende-se que o papel das profissionais era de "articuladores sociais” (JACOBI, 1989), ou seja, de propor e incentivar a identificação de temas/problemas para as discussões e de assessorar as crianças na busca de respostas aos problemas. Isso, de certa forma, contribuía para a conscientização e explicitação das questões do condomínio que se referiam aos interesses das crianças. Assim, como assessoras da Administração Mirim, as duas profissionais constituíam-se em "atores sociais relevantes" na identificação e reconhecimento dos valores de referência e na construção das demandas daquelas crianças (JACOBI, 1989).

Para as reuniões, eram convidadas todas as crianças moradoras, porém somente compareciam as que ocupavam os "cargos administrativos” e seus irmãos. Nestas reuniões, realizadas no salão infanto-juvenil, discutia-se as necessidades e problemas das crianças, em relação ao edifício. Os membros da Administração Mirim compareciam nos horários agendados e receberam uma pastinha, na qual realizavam suas anotações, tal como a redação de uma "ata"4.

Nestas reuniões, as crianças apresentaram sugestões de mudanças e adaptações nos materiais, brinquedos e jogos, visando a funcionalidade e conservação do salão, inclusive com participação nas reuniões de condomínio dos adultos. A Administração Mirim também ajudava a orientar as demais crianças moradoras, (durante as brincadeiras em conjunto, e de forma espontânea e natural), aos cuidados em geral. Isso demonstrava que, em parte, os objetivos iniciais estavam sendo atingidos, especialmente no tocante ao envolvimento e responsabilidade.

No mes de junho, a Administração Mirim conseguiu envolver várias outras crianças no planejamento e nos preparativos para uma grande festa junina, que se deu no mes seguinte. Assim, as crianças e alguns pais participaram da confecção de bandeirinhas e flores de papel que, depois, seriam utilizados na decoração do prédio. Também confeccionaram os convites da festa junina, desenhando e escrevendo, e encarregando-se de entregá-los em todos os 40 apartamentos, confirmando a presença dos moradores. Escolheram as atrações infantis da festa e participaram na confecção dos materiais (peixinhos para barraca de

2 Segundo NUNES (1989), carência é um atributo de um indivíduo determinado, sentimento elaborado a partir de processos de socialização, de vivências de precariedade, de sentimentos de dignidade violentada e da existência de desejos. A carência tem implicações sobre escolhas dos sujeitos, que são guiadas por valores. As carências podem ser sociais e intelectuais, variando em número e caráter conforme o estado geral de civilização de uma comunidade/cultura.

4 A atividade de registro das "atas" das reuniões possibilitou acompanhar o processo de desenvolvimento da linguagem escrita de uma das crianças (o sindico-mirim) que se encontrava em inicio de alfabetização e que mesclava desenhos e grafemas em seus registros, recorrendo ao apoio dos seus interlocutores para esclarecimento de suas dúvidas referentes à linguagem escrita. Posteriormente, sua mãe relatou às` coordenadoras os progressos que seu filho estava obtendo na escola e em seu processo de construção da leitura e da escrita, em decorrência de sua participação na Administração Mirim. 
pescaria; caixas-surpresa; cartões para o correioelegante, por exemplo) e na coordenação das "barracas" referentes a estas atividades, destinadas às crianças, durante a festa junina.

Neste período, a iniciativa passou a chamar a atenção dos moradores dos edifícios vizinhos que, na figura do síndico (adulto), agendaram uma reunião com a Administração Mirim para obter informações e instituir, também no seu condomínio, esta idéia. A imprensa local, por meio de um jornal impresso, também entrevistou o grupo e publicou uma reportagem. Uma empresa de televisão regional (São Carlos - SP) chegou a agendar uma reportagem, cancelada na última hora.

\section{ASPECTOS NEGATIVOS, DIFICULDADES E FATORES INTER VENIENTES}

A mobilização das crianças girou em torno do "fazer", em um campo de trabalho que, conforme aponta GOHN (1997), estava pouco ou nada preocupado com questões ideológicas ou políticas mais abrangentes, ainda que fossem referentes ao espaço do condomínio ou da comunidade (do bairro) onde o edifício se localizava. Assim, reforçou a noção do indivíduo participando, cada um fazendo a sua parte, porém isento de idealizações direcionadas à mobilização de um coletivo (HADDAD, 1999).

O “assédio" da imprensa, ao mesmo tempo em que demonstrava a curiosidade e o reconhecimento das pessoas em relação à Administração Mirim, também provocou tensões e expectativas, já que tanto crianças como as profissionais se viram levadas a cancelar compromissos de aulas e trabalhos, além de lançar mão do tempo livre de lazer na preparação para receber os interessados e a imprensa. Assim, vários encontros e reuniões extras foram realizados, outros foram agendados, cancelados, remarcados e desmarcados (em função da imprensa), causando sentimentos de frustração. Na experiência com a empresa de televisão, ficou clara a tendência e preferência da média pela cobertura, produção e veiculação de notícias de fatos negativos, de caráter contingencial, impactual e sensacionalista por vezes sem importância histórica - em detrimento da cobertura de temas relacionados à educação e participação social, por exemplo, dentre outras de interesse social, em conformidade com aspectos abordados por autores como COSTA (1994).

As dificuldades e retrocessos foram sentidos principalmente (e inicialmente) pelas duas coordenadoras.
Observava-se que os pais tratavam a Administração Mirim como uma iniciativa e responsabilidade à parte de seu papel como pais ou moradores. A não participação dos pais nas reuniões começou a ser vista como um aspecto deficitário, já que um dos objetivos das coordenadoras era, também, incentivar a aproximação e participação dos pais nas questões e brincadeiras dos filhos. Ao invés disso, alguns até aproveitavam o momento de reunião da Administração Mirim para sair, fazer compras, ir ao cabeleireiro, por exemplo, fazendo com que os investimentos pessoais das coordenadoras soassem como perda de tempo.

Cabe destacar, aqui, que não houve um trabalho específico direcionado ao envolvimento dos pais das crianças na proposta da Administração Mirim. Talvez se, desde o início da proposta, houvesse maior integração com as famílias moradoras do edifício, tivesse sido possível contar com estes sujeitos como parceiros e coresponsáveis da proposta. Isso seria interessante, não somente do ponto de vista de apoio e incentivo à crescente autonomia das crianças, mas também enquanto partilha de responsabilidade e de compromisso com as duas coordenadoras.

O envolvimento dos pais talvez pudesse vir a representar uma maneira de trabalhar para transformar os costumes daquelas famílias, melhor enfrentando os obstáculos que se impõem à legitimação dos instrumentos de participação popular e estreitando a relação entre educação política e cidadania ativa (BENEVIDES, 1998). A expectativa da mudança, segundo esse autor, se manifesta na exigência por direitos, pela democratização, por cidadania ativa, por maior participação política e por mudanças nos costumes de uma sociedade ainda marcada pela experiência do mando, do favor, da exclusão do privilégio.

A sensação de que a iniciativa não era expandida a outras crianças nem às famílias acabou por esvaziar a proposta de seu sentido mais coletivo. A Administração Mirim resumia-se às três crianças e às duas coordenadoras que, justamente por não serem mães e por questões de ordem pessoal, acabaram por se sentir sobrecarregadas pelas reuniões aos finais de semana, e passaram a reduzir a freqüência das reuniões.

Aos poucos, novas famílias com crianças foram mudando para o edifício, muitas delas eram locatárias e mostravam-se desprovidas do espírito de conservação e melhoria do patrimônio coletivo. O aumento do número de crianças no condomínio, em um momento em que diminuíam as reuniões da Administração Mirim, repetiu-se na ocorrência de danos e prejuízos aos materiais do salão de jogos infanto-juvenil, bem como em uso 
inadequado das dependências dos banheiros que serviam ao salão, causando entupimentos.

Assim, em Outubro de 1998, as coordenadoras redigiram uma carta aos moradores, destinada aos pais, solicitando atenção e colaboração na orientação de seus filhos quanto ao uso do salão. Na semana de 12 de Outubro (dia das crianças), foi organizado um Campeonato de Pebolim, envolvendo algumas crianças do edifício e também do prédio vizinho. Este evento contou com a adesão de poucos moradores.

Paralelamente, o excesso de aproximações e de convivência entre moradores adultos nas áreas comuns, e o fato de um morador exercer grande influência negativa sobre o grupo de moradores, acabou por gerar "fofocas", conflitos e discórdias de toda ordem, que vieram a "minar" e destruir as relações de amizade e fraternidade ali construídas.

Com as relações interpessoais extremamente desgastadas, as pessoas acabaram por se afastar socialmente ou mantiveram a convivência apenas em grupos reduzidos. Os adultos também deixaram de se envolver nos assuntos e de participar das reuniões do condomínio. Isso exerceu influência negativa sobre a disposição das coordenadoras e de todo o grupo de moradores, além das crianças que, guardadas as proporções, percebiam e sabiam o que estava se passando na relação entre os adultos.

Nos últimos dois anos, o salão permaneceu apenas como um espaço de uso das crianças, sem se constituir em tema ou razão de qualquer outra iniciativa no sentido de articulação das crianças e moradores.

A Administração Mirim deixou de existir na medida em que as coordenadoras afastaram-se da iniciativa e em que não havia outros adultos para apoiar e/ou referenciar as crianças.

A proposta específica, que nasceu das necessidades dos adultos em relação ao uso do salão infanto-juvenil, não conseguiu superar este enfoque localizado.

A Administração Mirim, enquanto atores sociais mirins, nunca criaram autonomia, nem para a identificação das próprias demandas e carências, necessária para o desenvolvimento de uma noção coletiva de direitos naquele condomínio, nem para a permanência das reuniões e propostas delas decorrentes.

Sem reais carências por parte das crianças, ficou o grupo desprovido de processos identitários (NUNES, 1989) capazes de definir as coletividades e os participantes daquela Adm. Mirim. Também as práticas que se desenvolveram sob a responsabilidade da Administração Mirim nunca objetivaram e nem conseguiram transcender as questões/problemas do imediatismo e do localismo, que, caso tivesse ocorrido, poderia constituir-se em um aspecto favorável no sentido de uma mudança qualitativa do modo de pensar a cidadania naquele grupo social (JACOBI, 1989).

\section{CONSIDERAÇÕES FINAIS}

A análise retrospectiva demonstra a viabilidade desta proposta, que tanto favoreceu o desenvolvimento individual como coletivo das crianças envolvidas. Elas tornaram-se mais atentas às questões coletivas e envolveram-se de forma participativa, também em outros eventos e assuntos do edifício, apresentando idéias e buscando alternativas para solução de problemas.

A proposta de Administração Mirim desponta como uma idéia interessante que apresenta contribuições para incentivar a participação social ativa e real, de crianças e adolescentes, a partir das oportunidades cotidianas, das relações familiares e dos diversos espaços de convívio social como, por exemplo, edifícios, condomínios residenciais, instituições educacionais, comunidades de bairro ou igrejas.

A análise das facilidades encontradas e das dificuldades enfrentadas possibilita a identificação e a sugestão de aspectos importantes a serem observados na caracterização de futuras propostas de Administrações Mirins, tais como:

- Partir das questões, necessidades e carências das próprias crianças/adolescentes;

- Buscar a expressão e o envolvimento de todas as crianças/adolescentes do espaço social;

- Envolver o entorno social a $\wedge$ fim $\wedge$ de construir uma rede de apoio;

- Envolver os pais para que suas boncepções e valores relacionados à cidadania também sejam transformados

- Abranger temas mais amplos e coletivos da comunidade em que se insere;

- Evitar limitar os obj etivos e ações ao imediatismo e localizacionistno;

- Focalizar perspectivas transformadoras e de um novo modo de pensar a cidania;

- Desenvolver uma identidade conciliando caracterização dos sujeitos, objetivos, necessidades e recursos;

- Desenvolver autonomia necessária à superação da dependência das "tutelas”, das "incubadoras”, dos aspectos externos e da mediação dos profissionais.

- As práticas de participação popular são reconhecidas por autores, como BENEVIDES (1998), pelo seu mérito 
de corrigir as involuções do regime democrático, ^de aperfeiçoamento da vivência democrática, e de perrnitir que as pessoas passem a se interessar diretamente pelos assuntos que Ihes $\wedge$ dizem respeito. Este trabalho mostrou a viabilidade destas práticas desde a infancia, a despeito das dificuldades que cada experiência localizada venha a enfrentar.

\begin{abstract}
Social participation is essential for the process of Health Promotion, and it must be motivated since childhood. The objective of this work is to present a retrospective analysis of the expenence of a Children Administration in a Residential Building, by focusing on its interfenng factors, possibilities and limits. Such experience was an anempt to mo^hvate children to participate actively and responsibly in the matters, decisions and subjects of the building which were part of their irnerests and necessities. The analysis shows that the Children Administration promoted the personal and collective development of tbose children, who got involved actively in other events and subjects of the building by presenting ideas and trying to solve problems. The analysis made it possible to identify important aspects to be observed in fuvnre Children Administration proposals as a contnbution to motivate citizenship and active and real social participation of children and teenagers in several living social environments.
\end{abstract}

Key words: social participation; citizenship; popular education.

\section{REFERENCIAS BIBLIOGRÁFICAS}

BENEVIDES M. V. M. A cidadania ativa. $3^{a}$ ed. São Paulo. Editora Ática, 1998. (Col. Ensaios 136)

COSTA, B.C.G. Jornalismo - controle de informação, conceito de notícia e a fetichização dos fatos. Revista Impulso, 7(15), Unimep/ Piracicaba, 1994.

GOHN, M G. Teoria dos movimentos sociais. paradigmas clássicos e contemporâneos. São Paulo: Ed. Loyola, 1997.

HADDAD, S. Mesa redonda: participação e cidadania na promoção da saúde. Anais do Vl Congresso Paulista de Saúde Pública, Águas de Lindóia, 1999.
JACOBI, P. Atores sociais e Estado: movimentos reinvindicatórios urbanos e Estado - dimensões da ação coletiva e efeitos político-institucionais no Brasil. Espaço \& Debates, 26: 1021, 1989.

MINISTÉRIO DA SAUDE. Promoção da Saúde. Brasilia DF, 2001.

NUNES, E. Carências urbanas, reivindicações sociais e valores democráticos. São Paulo, Lua Nova, 17: 67-92,1989.

Recebido em 05/08/2001 Aprovado em 14/08/2001 